\title{
Neuropeptide W Attenuates Oxidative Multi-Organ Injury in Rats Induced with Intra-Abdominal Sepsis
}

\section{Ali Emre Atici}

Marmara Universitesi Tip Fakultesi

Sevil Arabacı Tamer

Marmara Universitesi Tip Fakultesi

Hilal Nisva Levent

Marmara Universitesi Tip Fakultesi

İrem Peker Eyuboglu

Marmara Universitesi Tip Fakultesi

\section{Feriha Ercan}

Marmara Universitesi Tip Fakultesi

Mustafa Akkiprik

Marmara Universitesi Tip Fakultesi

Berrak Ç Yegen ( $\sim$ byegen@marmara.edu.tr)

Marmara University School of Medicine https://orcid.org/0000-0003-0791-0165

\section{Research Article}

Keywords: sepsis, oxidant injury, neuropeptide W, multi-organ damage

Posted Date: April 19th, 2021

DOl: https://doi.org/10.21203/rs.3.rs-401807/v1

License: (c) (1) This work is licensed under a Creative Commons Attribution 4.0 International License.

Read Full License

Version of Record: A version of this preprint was published at Inflammation on September 25th, 2021. See the published version at https://doi.org/10.1007/s10753-021-01545-5. 


\section{Abstract}

Sepsis leads to systemic hypotension, disturbed perfusion, inflammation and tissue toxicity in vital organs. Neuropeptide W (NPW) has modulatory effects in the control of blood pressure and inflammatory processes, implicating a potential beneficial effect against sepsis-induced oxidative damage. Under anesthesia, male Sprague Dawley rats underwent cecal ligation and puncture. Immediately after surgery, either saline or TNF-alpha inhibitor (etanercept; $1 \mathrm{mg} / \mathrm{kg}$ ) antibiotic (ceftriaxon; $100 \mathrm{mg} / \mathrm{kg}$ ) combination or NPW $(0.1,1$ or $3 \mu \mathrm{g} / \mathrm{kg})$ was given subcutaneously, and injections were repeated at 12th and 24th $\mathrm{h}$. The sham-operated control group was treated with saline at the same time points. All rats were euthanized at the 25 th $\mathrm{h}$ of surgery. Sepsis resulted in oxidative damage of the brain, heart, lung, liver and kidney. Elevations in blood urea nitrogen and alkaline phosphatase, showing renal and hepatic dysfunction, were not evident when septic rats were treated with NPW. NPW reduced serum levels of Creactive protein, corticosterone and interleukin-6, while histopathologically verified tissue damage in all the studied tissues was ameliorated. NPW treatment suppressed lipid peroxidation in the heart, lung and brain, and the depleted antioxidant GSH levels of the brain and heart were replenished by NPW. Moreover, sepsis-related neutrophil recruitment to liver and lung was also suppressed by NPW. Although survival rate of the rats was not significantly prolonged by NPW, most of these improvements in systemic and local inflammatory events were comparable with those reached by the etanercept and antibiotic combination, suggesting the therapeutic impact of NPW during the acute period of sepsis.

\section{Introduction}

Sepsis was recently redefined as a syndrome presenting with "life-threatening organ dysfunction due to dysregulated response of the host to infection" [1]. Despite the ongoing advances in monitoring, medical treatment and supportive care, sepsis still keeps its leading position as the cause of mortality in intensive care units and it remains accountable for the highest healthcare costs in the world [1, 2]. Intra-abdominal infections, as compared with the other sources of infection, are found to be associated with the highest mortality in septic patients [3]. Independent of the source of the infection, sepsis can lead to systemic hypotension and inflammation, which together yield to disturbed perfusion and tissue toxicity in several vital organs [4]. It has been reported that the incidence of liver failure due to sepsis is similar to that of the cardiovascular dysfunction, but less than the dysfunction of the respiratory, renal or nervous systems [5]. Multi-organ dysfunction in sepsis is characterized by the infiltration of leukocytes into the target tissues, enhanced generation of reactive oxygen species (ROS) and activation of several pro-inflammatory cytokines, all of which lead to lipid peroxidation, DNA damage and the resultant oxidative organ damage $[6,7]$. Accordingly, the vast majority of anti-sepsis research was mainly focused on the use of anti-oxidant and anti-cytokine compounds [8-12], but most of the results of these preclinical studies could not be successfully transformed to significant outcomes in the clinical settings. Thus, apart from the treatment strategies based on initial fluid resuscitation, anti-endotoxins, vasopressors and antibiotics [13, 14], no effective treatments for sepsis have been introduced yet, indicating the ongoing need for the development of novel treatment choices. 
Neuropeptide W (NPW), a newly isolated endogenous peptide expressed in the hypothalamic and brainstem neurons as well as in several peripheral organs, was suggested to mediate stress response by modulating the hypothalamus-pituitary-adrenal (HPA) axis $[15,16]$. NPW elevates blood pressure by centrally coordinated mechanisms $[17,18]$ and by directly regulating the vascular tone [19]. Moreover, administration of NPW was shown to alleviate inflammatory pain [20] and exert anti-oxidant and antiinflammatory effects $[21,22]$. Thus, considering the impact of NPW on the HPA axis and its modulatory effects in the control of blood pressure and inflammatory processes, our aim was to elucidate whether NPW could have beneficial effects against sepsis-induced oxidative multi-organ damage. Using biochemical and histopathological analyses of the brain, heart, lung, liver and kidney tissues of the septic rats, the effect of the exogenously administered NPW was evaluated in comparison with the effect of the treatment with anti-tumor necrosis (TNF)-a plus antibiotic combination.

\section{Materials And Methods}

\section{Animals and Drugs}

Adult male Sprague Dawley rats (200-250 g, 10-12 weeks old, $\mathrm{n}=67$ ) were supplied by the Marmara University (MU) Animal Center (DEHAMER) and housed in regular wire-bottom cages under conditions where humidity $(65-70 \%)$, temperature $\left(22 \pm 2^{\circ} \mathrm{C}\right)$ and light/dark cycles $(12 / 12$ hour) were kept standard. Rats were fed with standard rat chow and tap water ad libitum. All experimental protocols were approved by the MU Animal Care and Use Committee (approval date 04.06.2018, code: 52.2018.mar). All the experiments were performed in compliance with the Turkish law on the use of animals, ARRIVE guidelines and regarding the guidelines of the New York Academy of Sciences.

NPW was purchased from Phoenix Pharmaceuticals (USA), while TNF-a inhibitor (etanercept, Enbrel®) was purchased from Pfizer (USA) and ceftriaxone (Rocephin ${ }^{\circledR}$ ) was obtained from Roche (Switzerland). All the agents were diluted in physiological saline for the preparation of the chosen doses.

\section{Surgical Procedure}

Sepsis was introduced by the cecal ligation and puncture (CLP) technique, as described previously [23]. Under anesthesia (ketamine $100 \mathrm{mg} / \mathrm{kg}$ and xylazine $10 \mathrm{mg} / \mathrm{kg}$, intraperitoneally) and considering the aseptic conditions, a 3-cm midline laparotomy was performed with minimal dissection to expose the cecum along with the attached intestine. The cecum was ligated with $3-0$ silk ligatures, while the continuity of the intestinal tract was maintained. The cecum was perforated at two points using an 18gauge needle, and the cecum was then gently compressed for the extrusion of feces from both perforated points. The bowel was returned to the abdominal cavity and the incision was closed. The control group underwent a sham-operation, where laparotomy was performed, the cecum was manipulated but not ligated or perforated. To minimize variability between different experimenters, the CLP procedure was always performed by the same investigator with surgical proficiency. At the end of the operation, all rats were resuscitated with saline ( $3 \mathrm{ml} / 100 \mathrm{~g}$ body weight) subcutaneously and returned to their home cages. Post-surgically, rats had free access to water, but were deprived of food within the next $25 \mathrm{~h}$. 


\section{Experimental Design}

Immediately after the CLP-surgery, saline or TNF-alpha inhibitor (etanercept; $1 \mathrm{mg} / \mathrm{kg}$ ) plus antibiotic (ceftriaxon; $100 \mathrm{mg} / \mathrm{kg})(E T+C)$ or NPW $(0.1,1$ or $3 \mathrm{mg} / \mathrm{kg})$ was given subcutaneously, and the injections were repeated at the 12th and 24th $\mathrm{h}$. The rationale for the chosen dose of etanercept was based on a previous report showing its anti-inflammatory action against thermal injury-induced pulmonary damage [24], while the three doses of NPW were based on our studies showing the anti-inflammatory effects of the peptide [21, 22]. The sham-operated control group was treated with saline at the same time points (immediately after surgery, at the 12th and 24th h). When the rats did not survive within the 25-h followup period, additional CLP surgeries were done to have 7 to 9 rats in each experimental group. At the 25th h, surviving rats were decapitated and blood was withdrawn via cardiac puncture for the assessment of hepatic (aspartate transaminase, AST and alkaline phosphatase, ALP) and renal functions (blood urea nitrogen, BUN and creatinine) and for the measurement of the serum levels of C-reactive protein (CRP), interleukin-6 (IL-6), pro-calcitonin and corticosterone. Tissue samples of brain, lung, heart, liver and kidney were immediately removed and stored at $80^{\circ} \mathrm{C}$ for the determination of malondialdehyde (MDA) and glutathione (GSH) levels, myeloperoxidase (MPO) activity and nuclear factor kappa B (NFkB) mRNA expression. Additional samples of the tissues were fixed in $10 \%$ buffered $p$-formaldehyde for histological analysis.

\section{Biochemical measurements in the serum}

Serum levels of CRP, IL-6 pro-calcitonin and corticosterone were measured by using the rat ELISA kits (Elabscience Biotechnology Co. Ltd., USA) according to the manufacturer's instructions. Serum alkaline phosphatase (ALP), aspartate aminotransferase (AST), creatinine, and blood urea nitrogen (BUN) were measured by colorimetric assay using a Clinical System 700 analyzer (Beckman Instruments).

\section{Measurement of malondialdehyde and glutathione levels and myeloperoxidase activity in the tissues}

Tissue samples (brain, lung, heart, liver or kidney) were homogenized in 10 volumes of trichloroacetic acid (10\%) using a tissue homogenizer (IKA, T10 basic Ultra-Turrax, Handheld Homogenizer, Germany) and centrifuged for $15 \mathrm{~min}$ at $3000 \mathrm{~g}$ and $4^{\circ} \mathrm{C}$. The supernatant was removed and re-centrifugation was made at $10000 \mathrm{~g}$ for 8 minutes. MDA levels as indicators of lipid peroxidation were measured with a spectrophotometer and the results were expressed as nanomoles MDA/g tissue [25]. GSH measurements were performed using a modification of the Ellman protocol [26] and the results are expressed in $\mu \mathrm{mol}$ $\mathrm{GSH} / \mathrm{g}$ tissue. Myeloperoxidase (MPO) activity, which is an indicator of tissue neutrophil infiltration, was determined by spectrophotometry at $460 \mathrm{~nm}$ through the measurement of $\mathrm{H}_{2} \mathrm{O}_{2}$-dependent oxidation of odianisidine. $2 \mathrm{HCl}$. Enzyme activity was defined as the amount of MPO expressed as per gram of tissue weight [27].

\section{Gene expression analysis by Reverse Transcriptase- Quantitative Real-Time PCR (RT-qPCR)}


To extract RNA with the PureLink RNA Mini Kit (Invitrogen, USA) according to the manufacturer's instructions, $20 \mathrm{mg}$ of frozen tissue samples (brain, lung, heart, liver or kidney) were homogenized using a TissueLyser II (Qiagen, Hilden, Germany). Total RNA was measured using a NanoDrop 1000 Spectrophotometer (Fisher Thermo, Wilmington, DE, USA) and stored at $-80^{\circ} \mathrm{C}$. Then, a total of $1 \mu \mathrm{g}$ of RNA in $20 \mu \mathrm{l}$ was used to synthesize cDNA using High Capacity cDNA Reverse Transcription Kit (Applied Biosystems, Foster City, California, USA) following the manufacturer's instructions and stored at $-20^{\circ} \mathrm{C}$.

Expression levels of NfkB and $\beta$-actin were quantified by Quantitative Real Time-PCR (qPCR) assays in triplicate. TaqMan Universal Master Mix II with TaqMan Gene Expression Assays (Applied Biosystems, Foster City, California, USA) for NfkB and $\beta$-actin were used for performing qPCR reactions in Light Cycler 480 System (Roche, Germany) according to manufacturer's instructions. Relative expression was calculated with the comparative Ct method, $2-\Delta \Delta \mathrm{Ct}$, for each sample.

\section{Histopathological preparation and analysis}

For light microscopic investigations, brain, lung, heart, liver and kidney tissue samples were fixed in $10 \%$ formaldehyde and processed routinely before embedding in paraffin. Tissue sections $(4 \mu \mathrm{m})$ were stained with hematoxylin and eosin (H\&E) and all tissue sections were examined under a photomicroscope (Olympus BX51, Tokyo, Japan) for the evaluation of histopathological changes by an experienced histologist (F.E.) who was unaware of the treatment conditions. At least five microscopic areas were examined to score each specimen and the histological score of the organ was calculated using the semiquantitative scale outlined in Table 1 , where 0 , none; 1 , mild; 2 , moderate, 3 , severe $[23,28]$. Accordingly, the maximum score that could be reached was 6 for the brain and cardiac tissues, while in the lung, liver and kidney tissues the highest score that could be given was 9 . 
Table 1

Criteria for the microscopic scoring of tissue damage.

\begin{tabular}{|c|c|}
\hline Tissue & Appearance \\
\hline \multirow[t]{2}{*}{ Brain } & - Degeneration of neurons \\
\hline & - Vascular edema and hemorrhage \\
\hline \multirow[t]{3}{*}{ Lung } & - Alveolar structural disturbance \\
\hline & • Inflammatory cell infiltration \\
\hline & - Vascular congestion and interstitial edema \\
\hline \multirow[t]{2}{*}{ Heart } & •Inflammatory cell infiltration \\
\hline & - Vascular congestion and hemorrhage \\
\hline \multirow[t]{3}{*}{ Liver } & - Dilation and vacuolization of hepatocytes \\
\hline & - Vascular congestion and dilation of sinusoids \\
\hline & - Kupffer cell infiltration \\
\hline \multirow[t]{3}{*}{ Kidney } & - Degeneration of Bowman space and glomeruli \\
\hline & - Degeneration of proximal and distal tubules \\
\hline & - Vascular congestion, interstitial edema, inflammatory cell infiltration \\
\hline
\end{tabular}

\section{Statistical Analysis}

Statistical analysis was carried out using GraphPad Prism 9.0 (GraphPad Software, Inc., La Jolla, CA). After analyzing for normal distribution, the data were analyzed by one-way analysis of variance followed by post hoc Tukey multiple comparison test. Survival rates of the groups were compared using Chisquare test. All data were presented as mean \pm SEM and $p$ values were regarded as significant when less than 0.05 .

\section{Results}

\section{Survival rates of the septic rats}

Survival rate within $25 \mathrm{~h}$ after the CLP procedure was $66.7 \%(8 / 12)$ in the saline-treated septic rats, while the survival rate was $100 \%$ in the sham-operated control group $(8 / 8)(p<0.05)$. As compared to salinetreated CLP group, survival rate in the etanercept plus antibiotic $(E T+C)$-treated septic rats was significantly elevated to $100 \%(11 / 11 ; p<0.05)$. In the sepsis groups treated with either $0.1 \mu \mathrm{g} / \mathrm{kg}$ or $1 \mu \mathrm{g} / \mathrm{kg}$ dose of NPW, survival rates (both $9 / 14 ; 64.3 \%$ ) were not different than that of the saline-treated sepsis group. Although the survival in the septic rats treated with the $3 \mu \mathrm{g} / \mathrm{kg}$ dose of NPW was increased to $87.5 \%(7 / 8)$, this relatively higher survival rate was not statistically different than the survival of the saline-treated septic rats. 


\section{Systemic responses to sepsis: serum pro-calcitonin, IL-6, CRP and corticosterone levels of septic rats}

Serum pro-calcitonin levels measured at the 25 th $\mathrm{h}$ of the sepsis induction showed a tendency to increase, but no statistically significant difference was observed among the experimental groups (Table 2). The elevation in the pro-inflammatory cytokine IL-6 level of the saline-treated septic rats as compared to control group was not statistically significant, while treatment with ET $+C(p<0.01)$ or 1 $\mu \mathrm{g} / \mathrm{kg}$ dose of NPW $(\mathrm{p}<0.05)$ significantly reduced the IL-6 levels.

Table 2. Serum levels of pro-calcitonin, interleukin-6 (IL-6), alkaline phosphatase (ALP), aspartate transaminase (AST), blood urea nitrogen (BUN) and creatinine in the sham-operated control rats and in the septic rats treated with either saline or etanercept $(1 \mathrm{mg} / \mathrm{kg})+$ ceftriaxon $(100 \mathrm{mg} / \mathrm{kg})(E T+C)$ or neuropeptide $\mathrm{W}(0.1,1$ or $3 \mathrm{mg} / \mathrm{kg})$.

\begin{tabular}{|c|c|c|c|c|c|c|}
\hline & \multirow[t]{3}{*}{ Control } & \multicolumn{5}{|l|}{ SEPSIS } \\
\hline & & \multirow[t]{2}{*}{ Saline } & \multirow[t]{2}{*}{$\mathrm{ET}+\mathrm{C}$} & \multicolumn{3}{|c|}{ NPW (mg/kg) } \\
\hline & & & & 0.1 & 1 & 3 \\
\hline $\begin{array}{l}\text { Pro-calcitonin } \\
(\mathrm{pg} / \mathrm{ml})\end{array}$ & $\begin{array}{l}580.4 \pm \\
59.3\end{array}$ & $\begin{array}{l}693.0 \pm \\
45.2\end{array}$ & $\begin{array}{l}791.5 \pm \\
80.4\end{array}$ & $\begin{array}{l}745.4 \pm \\
88.5\end{array}$ & $\begin{array}{l}652.7 \pm \\
91.3\end{array}$ & $\begin{array}{l}768.6 \pm \\
99.4\end{array}$ \\
\hline IL-6 (pg/ml) & $\begin{array}{l}1097.0 \pm \\
82.0\end{array}$ & $\begin{array}{l}1691.0 \pm \\
310.7\end{array}$ & $\begin{array}{l}693.7 \pm \\
40.1^{++}\end{array}$ & $\begin{array}{l}1132.0 \pm \\
225.2\end{array}$ & $\begin{array}{l}821.4 \pm \\
84.8^{+}\end{array}$ & $\begin{array}{l}1166.0 \pm \\
186.1\end{array}$ \\
\hline ALP (U/L) & $\begin{array}{l}153.0 \pm \\
7.8\end{array}$ & $\begin{array}{l}208.5 \pm \\
16.7^{* *}\end{array}$ & $\begin{array}{l}172.4 \pm \\
22.8\end{array}$ & $\begin{array}{l}203.3 \pm \\
13.6^{* *}\end{array}$ & $\begin{array}{l}163.9 \pm \\
16.2\end{array}$ & $\begin{array}{l}164.7 \pm \\
20.59\end{array}$ \\
\hline AST (U/L) & $\begin{array}{l}132.8 \pm \\
9.6\end{array}$ & $\begin{array}{l}175.6 \pm \\
27.6\end{array}$ & $\begin{array}{l}273.6 \pm \\
45.9^{* *}\end{array}$ & $\begin{array}{l}174.8 \pm \\
14.6\end{array}$ & $\begin{array}{l}206.8 \pm \\
22.2\end{array}$ & $\begin{array}{l}236.4 \pm \\
33.4\end{array}$ \\
\hline BUN (mg/dl) & $11.7 \pm 0.5$ & $14.6 \pm 0.8$ & $17.0 \pm 2.8$ & $13.8 \pm 1.3$ & $15.3 \pm 2.5$ & $11.5 \pm 0.8$ \\
\hline $\begin{array}{l}\text { Creatinine } \\
\text { (mg/dl) }\end{array}$ & $\begin{array}{l}0.24 \pm \\
0.01\end{array}$ & $0.22 \pm 0.01$ & $\begin{array}{l}0.24 \pm \\
0.02\end{array}$ & $0.22 \pm 0.01$ & $\begin{array}{l}0.27 \pm \\
0.02\end{array}$ & $0.24 \pm 0.01$ \\
\hline
\end{tabular}

${ }^{\star \star} p<0.01$, compared to control group, $+p<0.05,++p<0.01$, compared to saline-treated sepsis group.

Compared to sham-operated control group, serum levels of both CRP $(p<0.05)$ and corticosterone $(p<$ 0.01 ) were significantly elevated in the saline-treated sepsis group (Fig. 1). However, three consecutive treatments with ET + C during the 25-h period following sepsis induction depressed the CRP and corticosterone responses back to control levels $(p<0.05)$. In the septic groups that have received NPW treatment $(0.1,1$ or $3 \mu \mathrm{g} / \mathrm{kg})$ on three occasions during the 25 -h period, CRP levels were not elevated and were similar to that of the control group. When compared with saline-treated sepsis group, NPW treatment 
at all the given 3 doses depressed the serum corticosterone $(p<0.05)$ back to the levels that were not different that of the control level.

\section{Changes in the oxidative brain injury of the septic rats}

In the saline-treated septic rats, brain MDA level showing lipid peroxidation was increased with respect to that of the control group $(p<0.01)$, while the antioxidant GSH content of the brain tissue was depleted ( $p$ $<0.001$ ), demonstrating that sepsis has resulted in oxidative brain injury (Fig. 3). Histological analyses showed increased numbers of degenerated neurons in the brain tissue as compared to regular brain morphology of the control rats (Fig. 2), and the histological scoring revealed an elevated damage score $(p<0.001$; Fig. 3). ET + C-treatment depressed MDA level and the histological score $(p<0.01)$ evident with a fewer number of degenerated neurons; but ET + C-treatment had no effect on the depleted GSH stores of the septic rats. Although the elevation in the MPO activity, indicative of neutrophil infiltration to the inflamed tissue, has not reached to a statistically different level in the saline-treated septic rats, in the ET + C-treated septic group MPO activity was significantly elevated $(p<0.05)$, suggesting that the inhibitory effect of ET $+C$ on sepsis-induced brain injury is accompanied by an enhanced recruitment of the neutrophils to the brain tissue. Similarly, sepsis-induced elevation in MPO activity was also further enhanced by the two higher doses of NPW $(p<0.05)$, while these two higher doses of NPW abolished sepsis-induced elevation in lipid peroxidation and histological scores, presenting with a decreased number of degenerated neurons. However, the lowest dose of NPW had no effect on sepsis-induced increase in MDA level or the histological score, but GSH content of the brain tissue was elevated back to the control level $(p<0.01)$. On the other hand, despite the reduction in the damage score or MDA level, brain GSH level was still depleted in the sepsis group treated with the $3 \mu \mathrm{g} / \mathrm{kg}$ dose of NPW.

\section{Changes in the oxidative cardiac injury of the septic rats}

Sepsis-induced cardiac injury was demonstrated with the presence of elevated MDA level $(p<0.05)$, which was accompanied by a reduction in GSH content $(p<0.05)$ (Fig. 4). Cardiac damage was further verified by an elevated histological score $(p<0.001)$, which was based on the scoring of a moderate degree of vascular congestion and a mild damage in cardiomyocytes (Figs. 2 \& 4). Treatment with ET + C reversed sepsis-induced changes in cardiac MDA $(p<0.05)$ and GSH levels, but the given histological score was still higher than that of the control group $(p<0.001)$. At all the three doses, NPW treatment abolished CLP-induced elevation in cardiac lipid peroxidation $(p<0.05-0.01)$, prevented the depletion of GSH stores, while histological damage scores were reduced $(p<0.05)$ as evident by mild vascular congestion and quite regular cardiomyocytes (Figs. 2 \& 4). MPO activity of the cardiac tissue was not altered by sepsis, and none of the treatments had any further effects.

\section{Changes in the oxidative lung injury of the septic rats}

As a consequence of sepsis, lung tissues of saline-treated septic rats presented with elevated MDA and MPO activity levels concomitant with a reduced GSH content ( $p<0.01-0.001$; Fig. 5). Histological analyses revealed severe hemorrhage, alveolar disturbance and inflammatory cell infiltration with highly elevated damage scores ( $p<0.001$; Figs. 2 \& 5). ET $+C$ treatment had no effect on sepsis-induced 
changes in MDA, MPO or GSH, but hemorrhage, alveolar disturbance and inflammatory cell infiltration were relatively mild, yielding a lower histological score $(p<0.01)$ in the lung tissues of ET + C-treated group. Similarly, mild vascular congestion, alveolar disturbance and inflammatory cell infiltration were observed in the NPW-treated ( 1 and $3 \mu \mathrm{g} / \mathrm{kg}$ ) sepsis groups. Moreover, in contrast to the absence of any effects by $E T+C$ treatment, sepsis-induced elevations in MDA $(0.1,1$ and $3 \mu \mathrm{g} / \mathrm{kg})$ and MPO activity $(0.1$ and $1 \mu \mathrm{g} / \mathrm{kg}$ ) levels were prevented in NPW-treated septic rats, and the levels were similar to those of the control group.

\section{Changes in the hepatic function and oxidative hepatic injury of the septic rats}

Serum ALP levels in the saline-treated septic rats were significantly elevated as compared to shamoperated control rats $(p<0.01$; Table 2), showing acute hepatic dysfunction. Except for the lowest dose of NPW, which resulted in a significant elevation with respect to the control group $(p<0.01)$, sepsis-induced elevation in ALP was not evident in ET + C-treated group or the septic groups treated with the two higher doses of NPW, demonstrating preserved hepatic function. Although AST levels of the septic rats were not different than those levels of the control group, AST level in the ET + C-treated sepsis group was elevated as compared to control group $(p<0.01)$, but it was not different than that of the saline-treated sepsis group. Histological examination revealed severe hepatocyte degeneration with vacuole formation, sinusoidal congestion and inflammatory cell infiltration in the portal triad region of the livers of the salinetreated septic rats, summing up a high level of damage score ( $p<0.001$; Figs. $2 \& 6)$. Although hepatic injury was not accompanied by enhanced lipid peroxidation or depleted GSH levels, an elevated level of MPO activity was present in the hepatic tissues of saline-treated septic rats $(p<0.001$; Fig. 6$)$. In the ET + C-treated sepsis group, a quite regular liver parenchyma with a small number of degenerated hepatocytes and mild sinusoidal congestion was observed, and the histological score was significantly reduced $(\mathrm{p}<$ 0.01). In parallel, sepsis-induced elevation in MPO activity was depressed by ET $+C$ treatment $(p<0.05)$, while MDA level, which was not altered in the septic rats, was reduced by ET $+C$ below the control level ( $p$ $<0.05)$. NPW treatment at all the given doses depressed MPO activity $(p<0.05)$ and the histological scores, but the significant reduction in damage score was observed at the highest dose of NPW $(p<0.05)$, demonstrating a mild degeneration of liver parenchyma, sinusoidal congestion and Kupffer cell activation. At this highest dose of NPW, hepatic GSH, which was not significantly altered by sepsis induction, was depressed to a significantly lower level as compared to those measured in the control $(\mathrm{p}<$ $0.01)$ and saline-treated septic rats $(p<0.05)$, suggesting that the hepatic antioxidant content was depleted in protecting hepatic tissue by NPW.

\section{Changes in the renal function and oxidative renal injury of the septic rats}

Despite that serum creatinine levels were similar among the experimental groups, BUN levels in the salinetreated septic rats were significantly elevated as compared to the sham-operated control rats $(p<0.01$; Table 2), demonstrating the presence of sepsis-induced renal dysfunction. On the other hand, BUN levels 
in the septic rats treated with ET + C or either of the three doses of NPW were not statistically different than that of the control group. When compared with those of the control rats, MDA and MPO activity levels were significantly elevated in both the saline-treated and ET + C-treated sepsis rats $(p<0.05 ;$ Fig. 7). Despite that renal GSH content was not altered by sepsis, ET + C treatment provided an elevation in renal GSH with respect to those of both control or saline-treated sepsis groups $(p<0.001)$. Similar to ET $+C$ treatment, sepsis-induced increases in lipid peroxidation and neutrophil infiltration in the kidney tissues were not changed by NPW treatment, but in contrast NPW had no effect on renal GSH level. Severe renal corpuscle degeneration with glomerular congestion and dilatation of Bowman space, severe tubular degeneration with luminal cell debris and interstitial vascular congestion were evident in the kidneys of saline-treated septic rats, reaching a high damage score ( $<<0.001$; Figs. $2 \& 7)$. ET + C-treated sepsis group presented with a mild glomerular and interstitial vascular congestion, decreased tubular degeneration with luminal cell debris in kidney. Similarly, lower and middle doses of NPW resulted in a moderate glomerular and interstitial vascular congestion, while a mild tubular congestion with decreased luminal cell debris was observed in the kidneys of septic rats treated with the highest dose of NPW, lowering the damage score $(p<0.01)$.

\section{Changes in the expression of NFkB mRNA in the target tissues of sepsis}

Despite a tendency to decrease, induction of sepsis did not significantly change NFkB mRNA expression levels in the brain, heart, lung or liver tissues (Fig. 8). However, in both saline-treated and NPW-treated (1 $\mu \mathrm{g} / \mathrm{kg}$ ) sepsis groups, NFkB mRNA levels of the kidney tissue were depressed with respect to control group $(p<0.05)$. On the other hand, NFkB expression in the lung tissues was significantly depressed when septic rats were treated by NPW $(0.1 \mu \mathrm{g} / \mathrm{kg}$ and $1 \mu \mathrm{g} / \mathrm{kg} ; \mathrm{p}<0.05$ and $p<0.01)$.

\section{Discussion}

The findings of the present study demonstrate that intra-abdominally initiated sepsis has resulted in oxidative damage of the brain, heart, lung, liver and kidney within the first $25 \mathrm{~h}$. During this period, treatment of the rats with NPW on three occasions reduced lipid peroxidation in the cardiac, pulmonary and cerebral tissues, while the depleted antioxidant GSH levels of the cerebral and cardiac tissues were replenished by NPW. NPW also suppressed the sepsis-related neutrophil recruitment to the hepatic and pulmonary tissues. Elevations in BUN and ALP, suggestive of renal and hepatic dysfunction, were not evident in the septic rats treated with NPW. Moreover, NPW treatment reduced the serum levels of CRP, corticosterone and the pro-inflammatory cytokine IL-6, while histopathologically verified tissue damage in all the studied tissues was ameliorated by NPW. Although survival rate of the rats was not significantly prolonged by NPW, most of these improvements in systemic and local inflammatory events were comparable with those reached by the etanercept and antibiotic combination, suggesting the therapeutic impact of NPW during the acute period of sepsis. 
Observations in the septic shock patients have identified that CRP is expected to increase within the first 24-48 hours following the initial inflammatory response [29], while pro-calcitonin is elevated at nearly 24 hours after the onset of sepsis and shows a peak at 24-48 $\mathrm{h}$ [30]. In the rats induced with CLP, we observed that serum CRP level showed a significant elevation at the 25th $\mathrm{h}$ of sepsis, while the increases in pro-calcitonin and the pro-inflammatory IL-6 have not reached to statistical significance. On the other hand, sepsis induction has also resulted in high levels of corticosterone, indicating an enhancement in hypothalamo-pituitary-adrenal (HPA) axis activity. It is well documented that the initial activation of HPA axis during a bacterial infection involves the participation of cytokines and other inflammatory mediators [31], while homeostatic activation of the HPA axis and the actions of glucocorticoids are frequently impaired during the late periods of sepsis [32]. On the other hand, immunohistochemical studies have indicated that central administration of NPW, which is abundantly found in the nerve cell bodies and fibers in the hypothalamic areas associated with the HPA axis, was suggested to modulate the activation of HPA axis through its receptors in the hypothalamic nuclei $[15,33]$. Furthermore, NPW was reported to directly stimulate corticosterone secretion by adrenocortical cells [34], while its intraperitoneal injection to healthy rats was also shown to increase plasma concentration of corticosterone [35]. However, in the present study, peripheral administration of NPW suppressed the synthesis of corticosterone that was increased by the upregulation of HPA axis activity via the inflammatory mediators of sepsis. Our findings suggest that peripherally administered NPW exerts an anti-inflammatory action, and thereby appears to control the release of inflammatory mediators that would exaggerate the HPA activity. During the progress of sepsis, serum levels of CRP, corticosterone and IL-6 were depressed in the septic rats treated with the antibiotic-anti-TNF-a combination, while analogous responses were obtained in NPW-treated septic rats, implicating that NPW may have comparable beneficial effects on the outcomes of polymicrobial sepsis.

Since sepsis-induced liver injury is associated with a high mortality, attenuation of liver damage and hepatic dysfunction is expected to improve the prognosis of septic patients $[5,36]$. It was reported that hepatic dysfunction, which occurs as a consequence of hemodynamic instability and the injury of the hepatocytes and canaliculi, occurs within the first $1-2 \mathrm{~h}$ following CLP surgery in rodents [37]. CLPinduced hepatic injury was verified by our findings, demonstrating a histologically evident severe damage of the liver and a 2-fold increase in neutrophil infiltration. On the other hand, sepsis even due to nonrespiratory causes can easily progress to acute respiratory distress syndrome, which is also associated with a great incidence of mortality in septic patients [38,39]. Infiltration of neutrophils to the lung tissue is reported to be the major mechanism in inducing pulmonary capillary endothelial and alveolar epithelial injury $[40,41]$. Our data support that acute pulmonary injury induced by intra-abdominal sepsis was accompanied by an enhanced infiltration of neutrophils to the lung tissue along with increased lipid peroxidation, while neutrophil infiltration or lipid peroxidation in the NPW-treated septic rats was not different than the control group, showing that the protective effect of NPW on the lung tissue involves the limitation of neutrophil-associated oxidative damage. In conjunction with that, NPW treatment ameliorated hepatic damage and prevented the elevation of ALP level, while facilitated neutrophil recruitment to the hepatic tissue with sepsis was totally abolished. 
Clinical studies have shown that cerebral and cardiac injury may occur as early manifestations of sepsisrelated organ damage and are also indicative of poor prognosis $[42,43]$. It was reported that sepsisinduced cardiac dysfunction is caused mainly by elevated inflammation along with depleted energy and attenuated adrenergic signaling [44]. The pathophysiology of sepsis-related encephalopathy involves reduced cerebral blood flow, disrupted blood-brain barrier and the resultant neuronal degeneration due to adverse effects of inflammatory mediators, but leukocyte accumulation does not occur in the brain during sepsis [42]. Our current findings showed that sepsis-induced neuronal injury is not accompanied by any change in the accumulation of neutrophils, but involves a significant depletion of antioxidant GSH. Previous reports have also stated that oxidative damage in the target organs is caused by an imbalanced endogenous enzymatic activity $[45,46]$, suggesting that application of antioxidants could have a potential in the treatment of sepsis [11]. In the present study, alleviation of sepsis-induced neuronal injury by NPW treatment was accompanied by the replenished GSH stores, suggesting a stimulatory effect of NPW on the endogenous antioxidant capacity of the cerebral tissue. Similar to that has occurred in the cerebral tissue, sepsis has resulted in cardiac injury and an accompanying GSH depletion, which were not evident when the rats were treated with NPW. Thus, our results indicate that the protective effect of NPW treatment on both the cardiac and neuronal injury is directly related with the regulatory effect of NPW on tissue antioxidant content. There is substantial clinical evidence confirming that bacterial sepsis is responsible of nearly half of the cases with acute renal failure, and the coexisting renal failure is indicative of high mortality due to sepsis [47, 48]. In our CLP-induced sepsis model, oxidative injury was observed with increased lipid peroxidation and neutrophil infiltration in the renal tissue, as well as an elevated BUN level, showing the deterioration of the renal functions. However, NPW treatment was not equally efficient in reducing oxidative damage of the kidney as it was in alleviating sepsis- associated injury of the other target organs, but some amelioration in the histopathological changes and renal dysfunction was still evident.

Our data demonstrate that repetitive administration of NPW during the progress of sepsis, alleviated oxidative damage in all the studied target tissues. In order to evaluate the contribution of NFkB activity in the protective effects of NPW, we assessed the NFkB mRNA expressions in the target organs injured by intraabdominal sepsis induction. NFkB plays a critical role in the pathophysiology of sepsis and its activation leads to transcript stabilization and translation of the pro-inflammatory mediators [49]. Apart from its central role in the synthesis of cytokines and chemokines, NFkB also amplifies the expression, activation and survival of the inflammatory cells [50-52]. In both animal models and in human subjects with sepsis, NFkB activity was reported to be markedly increased in every target organ of the sepsis, while higher mortality rate and worse clinical outcome were associated with higher levels of NFkB activity, showing the profound impact of NFkB activation on the development of multiple organ dysfunction [53]. When NFkB-dependent genes were knockout or NFkB-signaling pathways were blocked, animals were found to be more resistant to the development of sepsis and its septic complications. Moreover, it was postulated that inhibition or modulation of NFkB could be beneficial in alleviating the inflammatory response and associated organ failure [54-57]. Our findings revealed that mRNA expression levels of NFkB were not significantly altered in the tissues insulted by sepsis, except for the renal tissue. On the 
other hand, treatment with NPW did not further change the depressed NFkB mRNA expression in the kidneys, while a profound inhibition of NFkB mRNA expression was evident in the lung tissue of NPWtreated septic rats, suggesting that the protective effect of NPW on sepsis-induced pulmonary injury could be mediated by suppressing oxidative stress via the inhibition of NFkB signaling pathway. Similarly, it was previously shown that inhibition of NFkB activation reduced the expressions of cytokines and adhesion molecules, neutrophil recruitment and abolished microvascular endothelial barrier permeability in the lungs of septic rats [58]. Although we have not observed any changes in the NFkB mRNA expression of the other sepsis-injured tissues, contribution of NFkB activity to the inflammatory cascades in these organs and the role of NPW during the earlier or delayed periods of sepsis cannot be ruled out.

Intrathecal administration of NPW was shown to produce analgesia against the inflammatory pain produced by formalin injection into the paw of the rats, but mechanically or thermally induced pain was not suppressed by NPW [20], implicating that NPW could be alleviating pain via its anti-inflammatory action. However, a possible anti-inflammatory effect of NPW against pain-provoking stimuli or its peripheral use was not thoroughly investigated. We have recently demonstrated that peripherally administered NPW exerts neuroprotective and antioxidant effects in rat pups with hypoxic-ischemic brain injury [21], and protects against stress-induced gastric ulcer in rats [22]. The present study further verifies the anti-inflammatory effects of NPW in multiple tissues affected by sepsis, and supports the notion that NPW or its agonists could be good candidates for the treatment of inflammation and for the relief of inflammatory pain.

Our study has some limitations. Since earlier studies have suggested that estrogens could protect the target tissues against sepsis-induced oxidative injury [59], use of only male rats is a limitation and neglects any varying actions that could occur in female rats. Studying in female rats at different stages of menstrual cycle could provide novel information about the interaction of NPW with hypothalamopituitary-gonadal axis. On the other hand, the protective effects of NPW could involve its blood pressure regulating effects [17-19], but in our experimental design we could not evaluate whether circulatory shock due to sepsis was affected by NPW. Moreover, we compared the effects of NPW with those of antiTNF-a-antibiotic combination, but further experimental studies could be designed to investigate a possible synergistic effect.

In conclusion, our results revealed that NPW has effectively reduced oxidative stress in the target organs of rats subjected to acute CLP-sepsis. Although it seems unlikely that any single agent could reverse the severe and even lethal course of sepsis and provide a considerable clinical benefit, NPW and its agonists require further investigation for their novel therapeutic potential in alleviating organ dysfunction in various inflammatory diseases.

\section{Declarations}

\section{Acknowledgements}


Part of this work was presented at the Digestive Disease Week 2020, and published as an abstract (Gastroenterology 2020,158(6):S109).

\section{Funding}

The study was supported by a grant from the Marmara University Fund, Istanbul, TR (Project no. SAG-A130319-0087).

\section{Conflicts of interest/Competing interests}

The authors have no relevant financial or non-financial interests to disclose.

\section{Availability of data and material (data transparency)}

The data that support the findings of the present study are available from the corresponding author [BCY] upon request.

\section{Code availability (software application or custom code)}

Not applicable.

\section{Author contributions:}

- All the experiments were performed at the Marmara University School of Medicine, Departments of Physiology \& Histology and Medical Biology.

- All persons designated as authors qualify for authorship.

- All persons who qualify for authorship are listed.

- All authors agree to be accountable for all aspects of the work in ensuring that questions related to the accuracy or integrity of any part of the work are appropriately investigated and resolved.

Study conception \& design of work: Ali Emre Atıcı, Sevil Arabacı Tamer, Hilal Nişva Levent, İrem Peker Eyüboğlu, Feriha Ercan, Mustafa Akkiprik, Berrak Ç.Yeğen (all authors)

Data acquisition: Ali Emre Atıcı, Sevil Arabacı Tamer, Hilal Nişva Levent, İrem Peker Eyüboğlu

Analysis and data interpretation: all authors

Drafting of the manuscript: all authors

Critical revision: Berrak Ç. Yeğen

Approval of the final version of the manuscript: all authors.

\section{Ethics approval}


Marmara University Animal Care and Use Committee (approval date 04.06.2018, code: 52.2018.mar).

\section{Consent to participate}

Not applicable.

\section{Consent for publication}

Not applicable.

\section{References}

1. Singer, M., C. S. Deutschman, C. W. Seymour, M. Shankar-Hari, D. Annane, M. Bauer, R. Bellomo, G. R. Bernard, J.-D. Chiche, and C. M. Coopersmith. 2016. The third international consensus definitions for sepsis and septic shock (Sepsis-3). Jama 315:: 801-810.

2. Paoli, C. J., M. A. Reynolds, M. Sinha, M. Gitlin, and E. Crouser. 2018. Epidemiology and costs of sepsis in the United States-an analysis based on timing of diagnosis and severity level. Critical care medicine 46: 1889.

3. Chou, E. H., S. Mann, T.-C. Hsu, W.-T. Hsu, C.C.-Y. Liu, T. Bhakta, D. M. Hassani, and C.-C. Lee. 2020. Incidence, trends, and outcomes of infection sites among hospitalizations of sepsis: A nationwide study. PloS one 15: e0227752.

4. Rossaint, J., and A. Zarbock. 2015. Pathogenesis of multiple organ failure in sepsis. Critical Reviews $^{\text {TM }}$ in Immunology 35.

5. Yan, J., S. Li, and S. Li. 2014. The role of the liver in sepsis. Int Rev Immuno/ 33:: 498-510.

6. Barichello, T., J. J. Fortunato, Â.M. Vitali, G. Feier, A. Reinke, J. C. F. Moreira, J. Quevedo, and F. DalPizzol. 2006. Oxidative variables in the rat brain after sepsis induced by cecal ligation and perforation. Critical care medicine 34:: 886-889.

7. Hotchkiss, R. S., and I. E. Karl. 2003. The pathophysiology and treatment of sepsis. New England journal of medicine 348:: 138-150.

8. Dinarello, C. A., and E. Abraham. 2002. Does blocking cytokines in sepsis work? Am J Respir Crit Care Med 166:: 1156-1157.

9. Giustina, A. D., S. Bonfante, G. F. Zarbato, L. G. Danielski, K. Mathias, A. N. de Oliveira, Jr., L. Garbossa, T. Cardoso, M. E. Fileti, and R. J. De Carli, et al. 2018. Dimethyl Fumarate Modulates Oxidative Stress and Inflammation in Organs After Sepsis in Rats. Inflammation 41: 315-327.

10. Osuchowski, M. F., K. Welch, J. Siddiqui, and D. G. Remick. 2006. Circulating cytokine/inhibitor profiles reshape the understanding of the SIRS/CARS continuum in sepsis and predict mortality. $J$ Immunol 177:: 1967-1974.

11. Ritter, C., M. E. Andrades, A. Reinke, S. Menna-Barreto, J. C. F. Moreira, and F. Dal-Pizzol. 2004. Treatment with $\mathrm{N}$-acetylcysteine plus deferoxamine protects rats against oxidative stress and improves survival in sepsis. Critical care medicine 32:: 342-349. 
12. Victor, V. M., M. Rocha, and J. V. Esplugues. 2005. Role of free radicals in sepsis: antioxidant therapy. Current pharmaceutical design 11:: 3141-3158.

13. Cinel, I., U. S. Kasapoglu, F. Gul, and R. P. Dellinger. 2020. The initial resuscitation of septic shock. J Crit Care 57:: 108-117.

14. Schmidt, G. A., J. Mandel, P. Parsons, D. Sexton, R. Hockberger, and G. Finlay. 2018. Evaluation and management of suspected sepsis and septic shock in adults. Uptodate Online 1-29.

15. Niimi, M., and K. Murao. 2005. Neuropeptide W as a stress mediator in the hypothalamus. Endocrine $27:: 51-54$.

16. Yan, F., R. Wang, S. Li, X. Zhao, Y. Jiang, L. Liu, J. Fang, X. Zhen, P. Lazarovici, and W. Zheng. 2020. Fox03a suppresses neuropeptide $W$ expression in neuronal cells and in rat hypothalamus and its implication in hypothalamic-pituitary-adrenal (HPA) axis. Int J Biol Sci 16:: 2775-2787.

17. Ji, L., H. Zhu, H. Chen, W. Fan, J. Chen, J. Chen, G. Zhu, and J. Wang. 2015. Modulation of CaV1. 2 calcium channel by neuropeptide $\mathrm{W}$ regulates vascular myogenic tone via $\mathrm{G}$ protein-coupled receptor 7. Journal of hypertension 33:: 2431-2442.

18. Yu, N., C. Chu, T. Kunitake, K. Kato, M. Nakazato, and H. Kannan. 2007. Cardiovascular actions of central neuropeptide W in conscious rats. Regulatory peptides 138:: 82-86.

19. Pate, A. T., G. L. Yosten, and W. K. Samson. 2013. Neuropeptide W increases mean arterial pressure as a result of behavioral arousal. American Journal of Physiology-Regulatory, Integrative and Comparative Physiology 305:: R804-R810.

20. Yamamoto, T., O. Saito, K. Shono, and S. Tanabe. 2005. Anti-hyperalgesic effects of intrathecally administered neuropeptide $\mathrm{W}-23$, and neuropeptide $\mathrm{B}$, in tests of inflammatory pain in rats. Brain Res 1045:: 97-106.

21. Koyuncuoglu, T., B. E. Ipek, E. K. Dertsiz, D. Akakin, M. Yuksel, and B. C. Yegen: The Neuroprotective Effects of Neuropeptide W in Newborn Rats with Cerebral Palsy. In ACTA PHYSIOLOGICA. WILEY 111 RIVER ST, HOBOKEN 07030 - 5774, NJ USA. 2019. 87-87.

22. Tamer, S. A., S. Akbulut, D. Akakin, and B. C. Yegen: Protective Effects of Neuropeptide-W on StressInduced Gastric Ulcer in Rats. In ACTA PHYSIOLOGICA. WILEY 111 RIVER ST, HOBOKEN 07030 5774, NJ USA. 2019. 116-116.

23. Şener, G., H. Toklu, C. Kapucu, F. Ercan, G. Erkanlı, and A. Kaçmaz, M. Tilki and B.Ç. Yeğen. 2005. Melatonin protects against oxidative organ injury in a rat model of sepsis. Surgery today 35: 52-59.

24. Şehirli, A.Ö. 2011. Etanercept protects remote organ damage in a rat model of thermal injury.

25. Casini, A., M. Ferrali, A. Pompella, E. Maellaro, and M. Comporti. 1986. Lipid peroxidation and cellular damage in extrahepatic tissues of bromobenzene-intoxicated mice. The American journal of pathology 123: 520.

26. Aykaç, G., M. Uysal, A. S. Yalçin, N. Koçak-Toker, A. Sivas, and H. Öz. 1985. The effect of chronic ethanol ingestion on hepatic lipid peroxide, glutathione, glutathione peroxidase and glutathione transferase in rats. Toxicology 36:: 71-76. 
27. Solmaz, A., E. Bahadır, O. B. Gülçiçek, H. Yiğitbaş, A. Çelik, A. Karagöz, D. Özsavcı, and S. Şirvancı and B.Ç. Yeğen. 2016. Nesfatin-1 improves oxidative skin injury in normoglycemic or hyperglycemic rats. Peptides 78: 1-10.

28. Demling, R., C. LaLonde, J. Knox, Y. Youn, D. Zhu, and R. Daryani. 1991. Fluid resuscitation with deferoxamine prevents systemic burn-induced oxidant injury. The Journal of trauma 31:: 538-543. discussion 543.

29. Du Clos, T. W., and C. Mold. 2004. C-reactive protein. Immunologic research 30:: 261-277.

30. Meisner, M. 2014. Update on procalcitonin measurements. Annals of laboratory medicine 34:: 263.

31. Turrin, N. P., and S. Rivest. 2004. Unraveling the molecular details involved in the intimate link between the immune and neuroendocrine systems. Experimental Biology and Medicine 229:: 9961006.

32. Bornstein, S. R. 2009. Predisposing factors for adrenal insufficiency. New England Journal of Medicine 360:: 2328-2339.

33. Fang, R., J. Su, L. Zheng, M. Jin, Y. Hou, Z. Ma, T. Guo, S. Zhu, X. Ma, and E. Ahmed. 2015. Cloning and distribution of neuropeptide $\mathrm{W}$ and its receptors in pigs. Research in veterinary science 101:: 106-116.

34. Mazzocchi, G., P. Rebuffat, A. Ziolkowska, G. Rossi, L. Malendowicz, and G. Nussdorfer. 2005. G protein receptors 7 and 8 are expressed in human adrenocortical cells, and their endogenous ligands neuropeptides $B$ and $w$ enhance cortisol secretion by activating adenylate cyclase-and phospholipase C-dependent signaling cascades. The Journal of Clinical Endocrinology \& Metabolism 90:: 3466-3471.

35. Hochol, A., A. S. Belloni, M. Rucinski, A. Ziolkowska, R. Di Liddo, G. G. Nussdorfer, and L. K. Malendowicz. 2006. Expression of neuropeptides $B$ and $W$ and their receptors in endocrine glands of the rat. International journal of molecular medicine 18:: 1101-1106.

36. Liang, H., X. Ding, Y. Yu, H. Zhang, L. Wang, Q. Kan, S. Ma, F. Guan, and T. Sun. 2019. Adipose-derived mesenchymal stem cells ameliorate acute liver injury in rat model of CLP induced-sepsis via sTNFR1. Experimental cell research 383: 111465.

37. Recknagel, P., F. A. Gonnert, M. Westermann, S. Lambeck, A. Lupp, A. Rudiger, A. Dyson, J. E. Carré, A. Kortgen, and C. Krafft. 2012. Liver dysfunction and phosphatidylinositol-3-kinase signalling in early sepsis: experimental studies in rodent models of peritonitis. PLoS Med 9: e1001338.

38. Erickson, S. E., G. S. Martin, J. L. Davis, M. A. Matthay, and M. D. Eisner. 2009. Recent trends in acute lung injury mortality: 1996-2005. Critical care medicine 37: 1574.

39. Johnson, E. R., and M. A. Matthay. 2010. Acute lung injury: epidemiology, pathogenesis, and treatment. Journal of aerosol medicine and pulmonary drug delivery 23:: 243-252.

40. Brown, K., S. Brain, J. Pearson, J. Edgeworth, S. Lewis, and D. Treacher. 2006. Neutrophils in development of multiple organ failure in sepsis. The Lancet 368:: 157-169.

41. Matthay, M. A., and R. L. Zemans. 2011. The acute respiratory distress syndrome: pathogenesis and treatment. Annu Rev Pathol 6:: 147-163. 
42. Papadopoulos, M. C., D. C. Davies, R. F. Moss, D. Tighe, and E. D. Bennett. 2000. Pathophysiology of septic encephalopathy: a review. Crit Care Med 28:: 3019-3024.

43. Sonneville, R., F. Verdonk, C. Rauturier, I. F. Klein, M. Wolff, D. Annane, F. Chretien, and T. Sharshar. 2013. Understanding brain dysfunction in sepsis. Ann Intensive Care 3: 15.

44. Drosatos, K., A. Lymperopoulos, P. J. Kennel, N. Pollak, P. C. Schulze, and I. J. Goldberg. 2015. Pathophysiology of sepsis-related cardiac dysfunction: driven by inflammation, energy mismanagement, or both? Curr Heart Fail Rep 12:: 130-140.

45. Andrades, M., C. Ritter, M. R. de Oliveira, E. L. Streck, J. C. F. Moreira, and F. Dal-Pizzol. 2011. Antioxidant treatment reverses organ failure in rat model of sepsis: role of antioxidant enzymes imbalance, neutrophil infiltration, and oxidative stress. Journal of surgical research 167: e307-e313.

46. Ritter, C., M. Andrades, M. L. C. Frota, F. Bonatto, R. A. Pinho, M. Polydoro, F. Klamt, C. T. Pinheiro, S. S. Menna-Barreto, and J. C. F. Moreira. 2003. Oxidative parameters and mortality in sepsis induced by cecal ligation and perforation. Intensive care medicine 29:: 1782-1789.

47. Matejovic, M., J. Chvojka, J. Radej, L. Ledvinova, T. Karvunidis, A. Krouzecky, and I. Novak. 2011. Sepsis and acute kidney injury are bidirectional. Contrib Nephrol 174:: 78-88.

48. Peerapornratana, S., C. L. Manrique-Caballero, H. Gómez, and J. A. Kellum. 2019. Acute kidney injury from sepsis: current concepts, epidemiology, pathophysiology, prevention and treatment. Kidney Int 96:: 1083-1099.

49. Kawai, T., and S. Akira. 2010. The role of pattern-recognition receptors in innate immunity: update on Toll-like receptors. Nat Immunol 11:: 373-384.

50. Han, S.-J., H.-M. Ko, J.-H. Choi, K. H. Seo, H.-S. Lee, E.-K. Choi, I.-W. Choi, H.-K. Lee, and S.-Y. Im. 2002. Molecular mechanisms for lipopolysaccharide-induced biphasic activation of nuclear factor-KB (NFKB). Journal of Biological Chemistry 277:: 44715-44721.

51. Hayden, M. S., A. P. West, and S. Ghosh. 2006. NF-kappaB and the immune response. Oncogene 25:: $6758-6780$.

52. Rossi, A., J. Hallett, D. Sawatzky, M. Teixeira, and C. Haslett: Modulation of granulocyte apoptosis can influence the resolution of inflammation. Portland Press Ltd. 2007.

53. Liu, S. F., and A. B. Malik. 2006. NF-kappa B activation as a pathological mechanism of septic shock and inflammation. Am J Physiol Lung Cell Mol Physiol 290:: L622-LI645.

54. Abraham, E. 2003. Nuclear factor-kappaB and its role in sepsis-associated organ failure. J Infect Dis 187 (Suppl 2:): S364-S369.

55. Li, X., J. Su, X. Cui, Y. Li, A. Barochia, and P. Q. Eichacker. 2009. Can we predict the effects of NFkappaB inhibition in sepsis? Studies with parthenolide and ethyl pyruvate. Expert Opin Investig Drugs 18:: 1047-1060.

56. Pikarsky, E., and Y. Ben-Neriah. 2006. NF-кB inhibition: a double-edged sword in cancer? European journal of cancer 42:: 779-784. 
57. Shen, L., H. Mo, L. Cai, T. Kong, W. Zheng, J. Ye, J. Qi, and Z. Xiao. 2009. Losartan prevents sepsisinduced acute lung injury and decreases activation of nuclear factorkB and mitogen-activated protein kinases. Shock (Augusta, Ga.) 31:: 500-506.

58. Liu, S. F., X. Ye, and A. B. Malik. 1999. Pyrrolidine dithiocarbamate prevents I-kappaB degradation and reduces microvascular injury induced by lipopolysaccharide in multiple organs. Mol Pharmacol 55:: 658-667.

59. Sener, G., S. Arbak, P. Kurtaran, N. Gedik, and B. C. Yeğen. 2005. Estrogen protects the liver and intestines against sepsis-induced injury in rats. $J$ Surg Res 128:: 70-78.

\section{Figures}



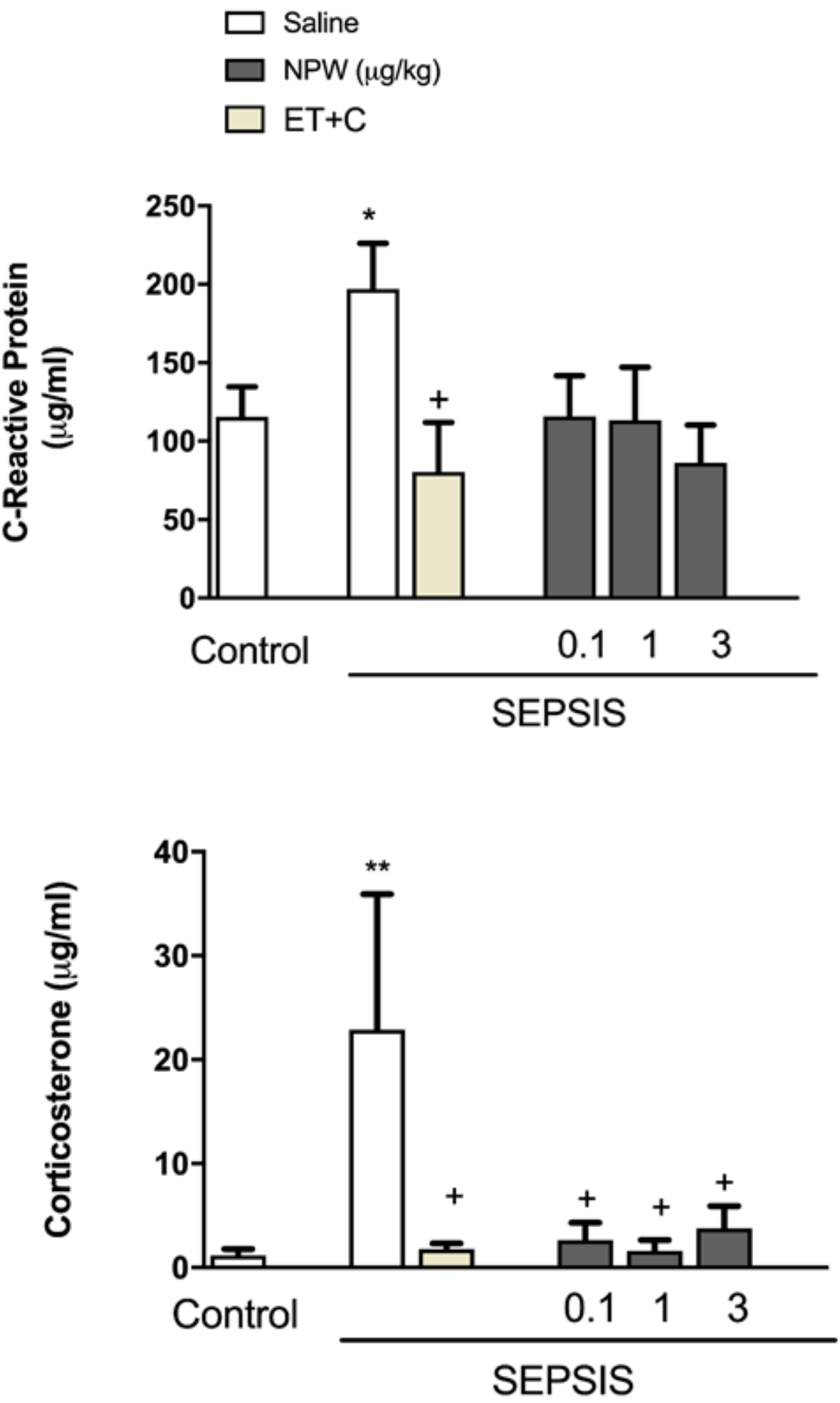

Figure 1

Serum levels of C-reactive protein and corticosterone in the control rats and septic rats injected subcutaneously with either saline, etanercept plus antibiotic $(E T+C)$ or neuropeptide W (NPW, 0.1, 1 and 3 $\mu \mathrm{g} / \mathrm{kg}$ ) immediately after sepsis induction, and at the 12th and 24th $\mathrm{h}$. ${ }^{*} \mathrm{p}<0.05,{ }^{*} \mathrm{p}<0.01$, compared to control group, $+p<0.05$, compared to saline-treated sepsis group. 


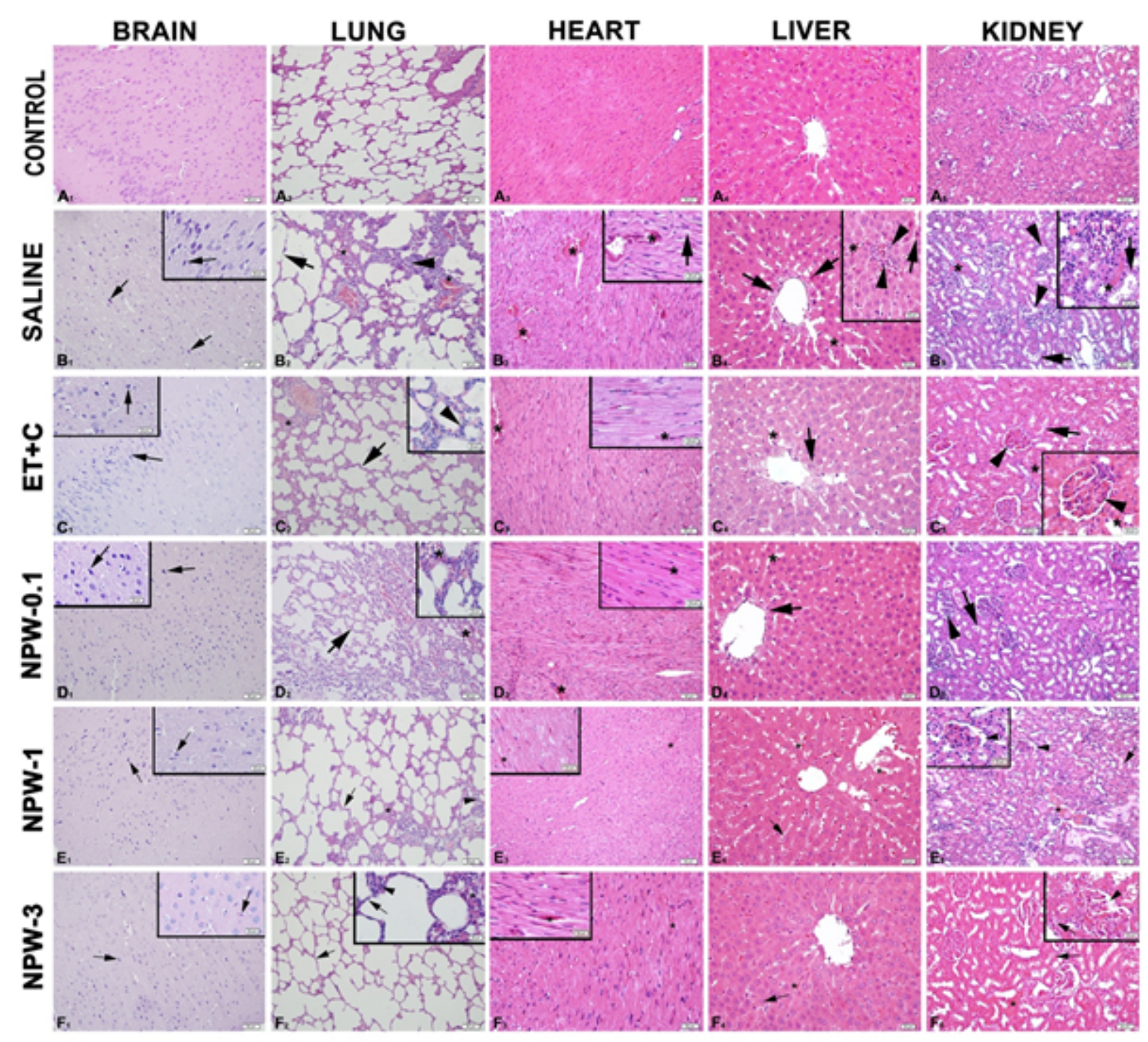

\section{Figure 2}

Representative light micrographs of the experimental groups. Regular brain (A1), lung (A2), heart (A3), liver parenchyma (A4) and kidney cortex (A5) are seen in the control group. Degenerated neurons (arrow) in brain (B1), severe hemorrhage $\left(^{*}\right)$, alveolar degeneration (arrow) and inflammatory cells (arrowhead) in lung parenchyma (B2), moderate vascular congestion $\left(^{*}\right)$ and degenerated cardiomyocytes (arrow) in heart (B3), severe degenerate hepatocytes (arrow), sinusoidal congestion (asterisk) and inflammatory cells (arrowhead) in portal triad region in liver (B4), severe renal corpuscle degeneration with glomerular congestion and dilatation of Bowman space (arrowhead), tubular degeneration (arrow) and interstitial vascular congestion (asterisk) in kidney (B5) are seen in the sepsis group. A few numbers of degenerated neurons (arrow) in brain (C1), mild hemorrhage $\left(^{*}\right)$ and alveolar disturbance (arrow) in lung (C2), quite regular heart morphology (C3) with mild vascular congestion $\left(^{*}\right)$, a few numbers of degenerated hepatocytes (arrow) and mild sinusoidal congestion (asterisk) in liver (C4), mild glomerular (arrowhead) and interstitial (arrow) vascular congestion, decreased tubular degeneration (arrow) in kidney (C5) are seen in ET+C-treated sepsis groups. Decreased number of degenerated neurons (arrow) in brain (D1-F1), moderate hemorrhage $\left(^{(}\right)$, mild alveolar degeneration (arrow) and inflammatory cells (arrowhead) in lung 
parenchyma (D2-F2), decreased vascular congestion (*) and regular cardiomyocytes in heart (D3-F3), a few number of degenerated hepatocytes (arrow) and mild sinusoidal congestion (asterisk) in liver (D4F4), moderate glomerular (arrowhead) and interstitial (asterisk) vascular congestion, mild tubular congestion (arrow) in kidney (D5-F5) are seen in $0.1 \mu \mathrm{g}, 1 \mu \mathrm{g}$ and $3 \mu \mathrm{g} \mathrm{NPW-treated} \mathrm{sepsis} \mathrm{groups.} \mathrm{H \& E}$ staining.
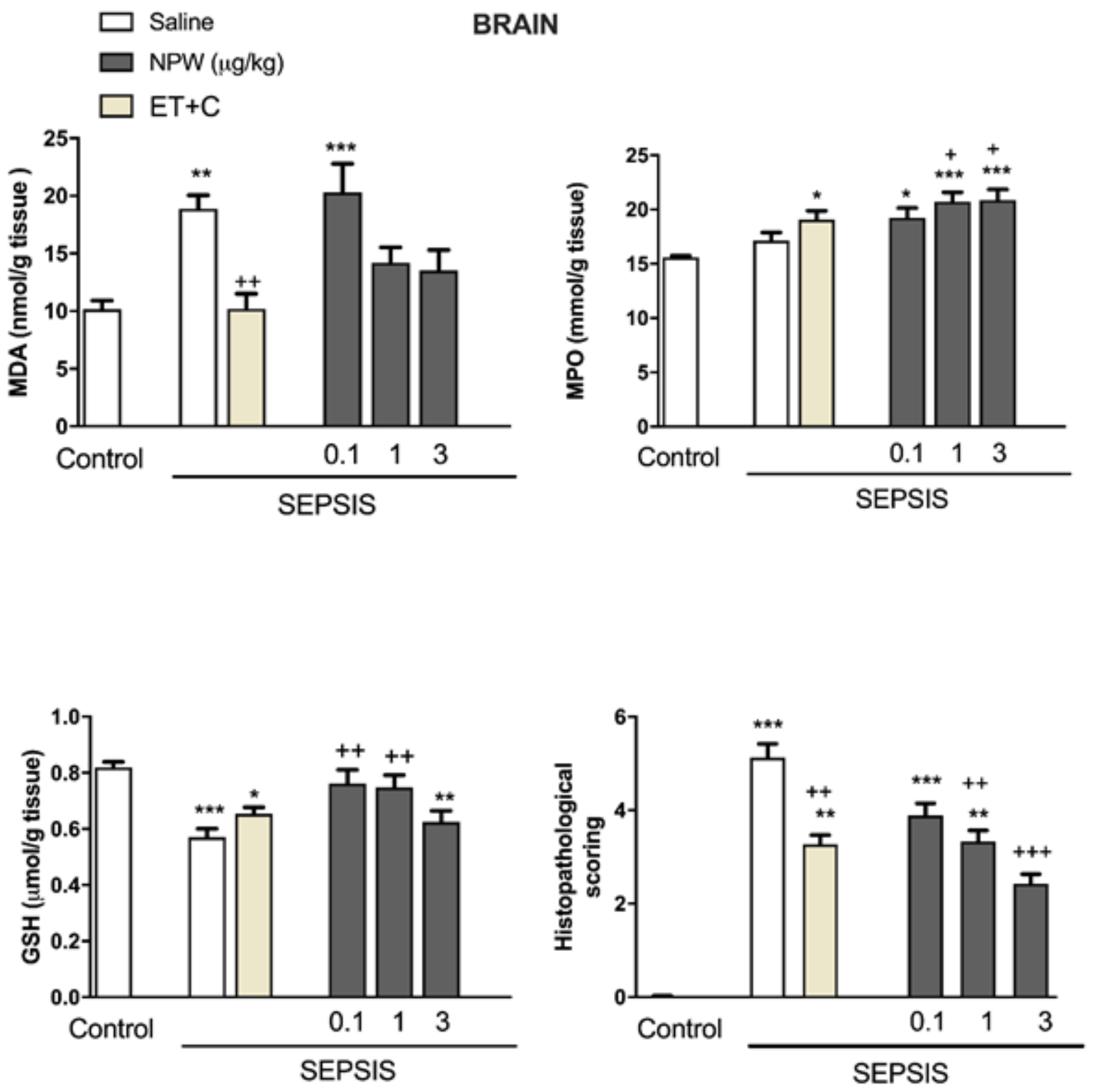

Figure 3

Levels of malondialdehyde (MDA), myeloperoxidase (MPO) activity, glutathione (GSH) and histopathological scores in the brain tissues of control rats and septic rats injected subcutaneously with either saline, etanercept plus antibiotic $(E T+C)$ or neuropeptide W (NPW, 0.1, 1 and $3 \mu \mathrm{g} / \mathrm{kg}$ ) immediately after sepsis induction, and at the 12th and 24th $h .{ }^{*} p<0.05$, ${ }^{* *} p<0.01,{ }^{* \star *} p<0.001$ compared to control group, $+p<0.05,++p<0.01,+++p<0.001$, compared to saline-treated sepsis group. 

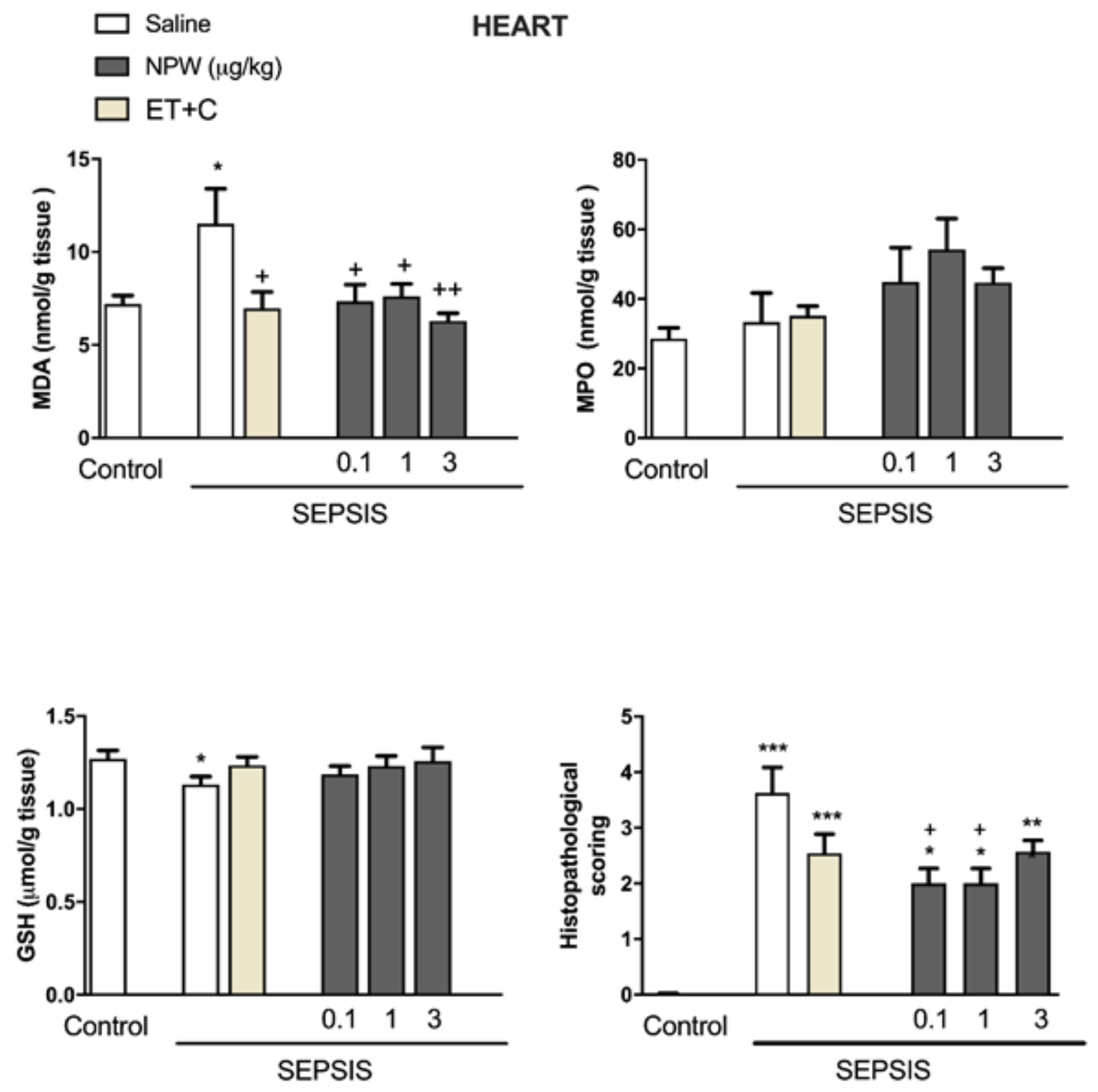

Figure 4

Levels of malondialdehyde (MDA), myeloperoxidase (MPO) activity, glutathione (GSH) and histopathological scores in the heart tissues of control rats and septic rats injected subcutaneously with either saline, etanercept plus antibiotic (ET+C) or neuropeptide W (NPW, 0.1, 1 and $3 \mu \mathrm{g} / \mathrm{kg}$ ) immediately after sepsis induction, and at the 12th and 24th $\mathrm{h} .{ }^{*} \mathrm{p}<0.05$, ${ }^{* \star} \mathrm{p}<0.01,{ }^{* \star *} \mathrm{p}<0.001$ compared to control group, $+p<0.05,++p<0.01$, compared to saline-treated sepsis group. 

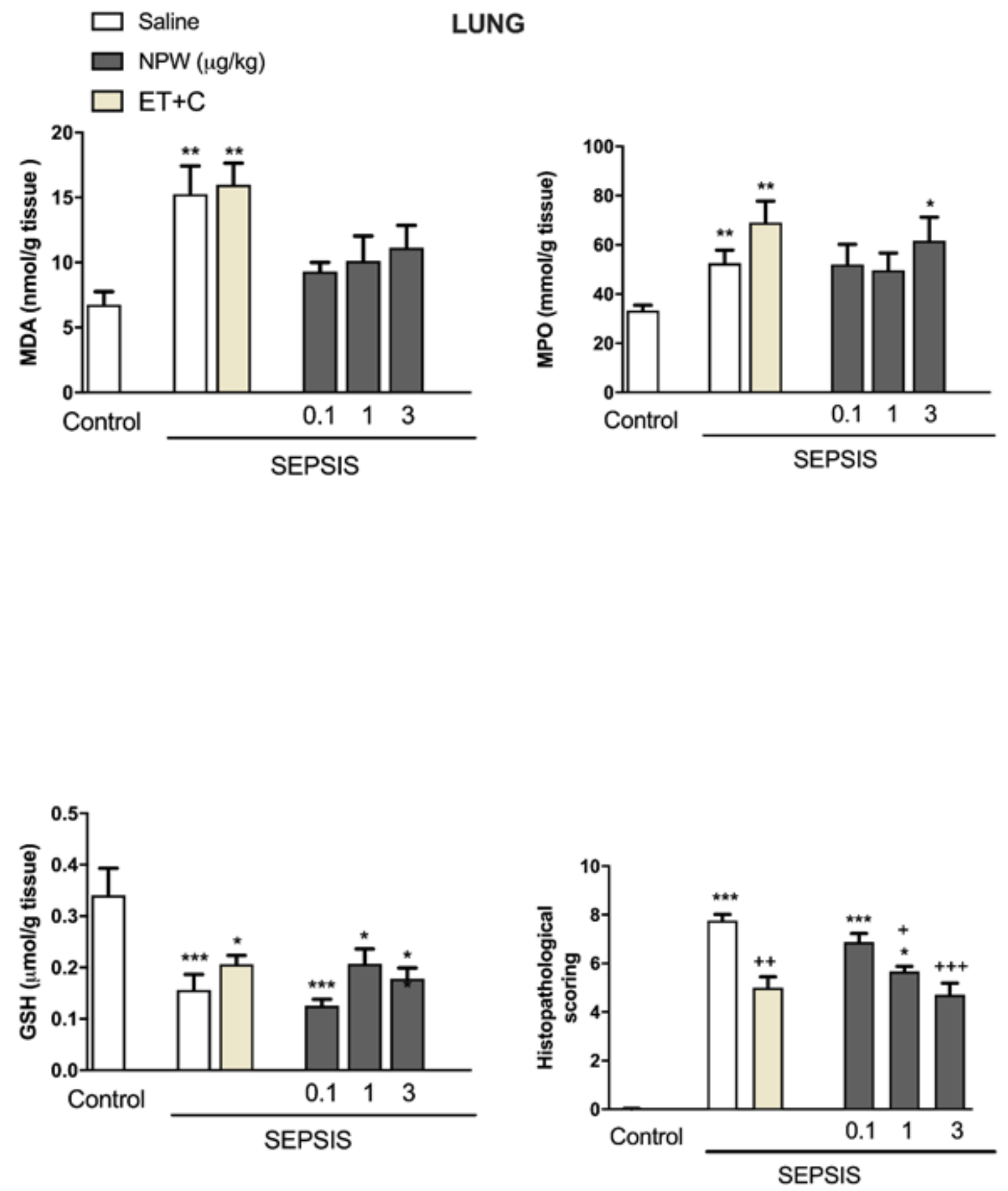

Figure 5

Levels of malondialdehyde (MDA), myeloperoxidase (MPO) activity, glutathione (GSH) and histopathological scores in the lung tissues of control rats and septic rats injected subcutaneously with either saline, etanercept plus antibiotic $(E T+C)$ or neuropeptide W (NPW, 0.1, 1 and $3 \mu \mathrm{g} / \mathrm{kg}$ ) immediately after sepsis induction, and at the 12th and 24th $h .{ }^{*} p<0.05$, ${ }^{\star \star} p<0.01,{ }^{* \star *} p<0.001$ compared to control group, $+p<0.05,+++p<0.001$, compared to saline-treated sepsis group. 
Saline

$\square \mathrm{NPW}(\mu \mathrm{g} / \mathrm{kg})$

$\square \mathrm{ET}+\mathrm{C}$
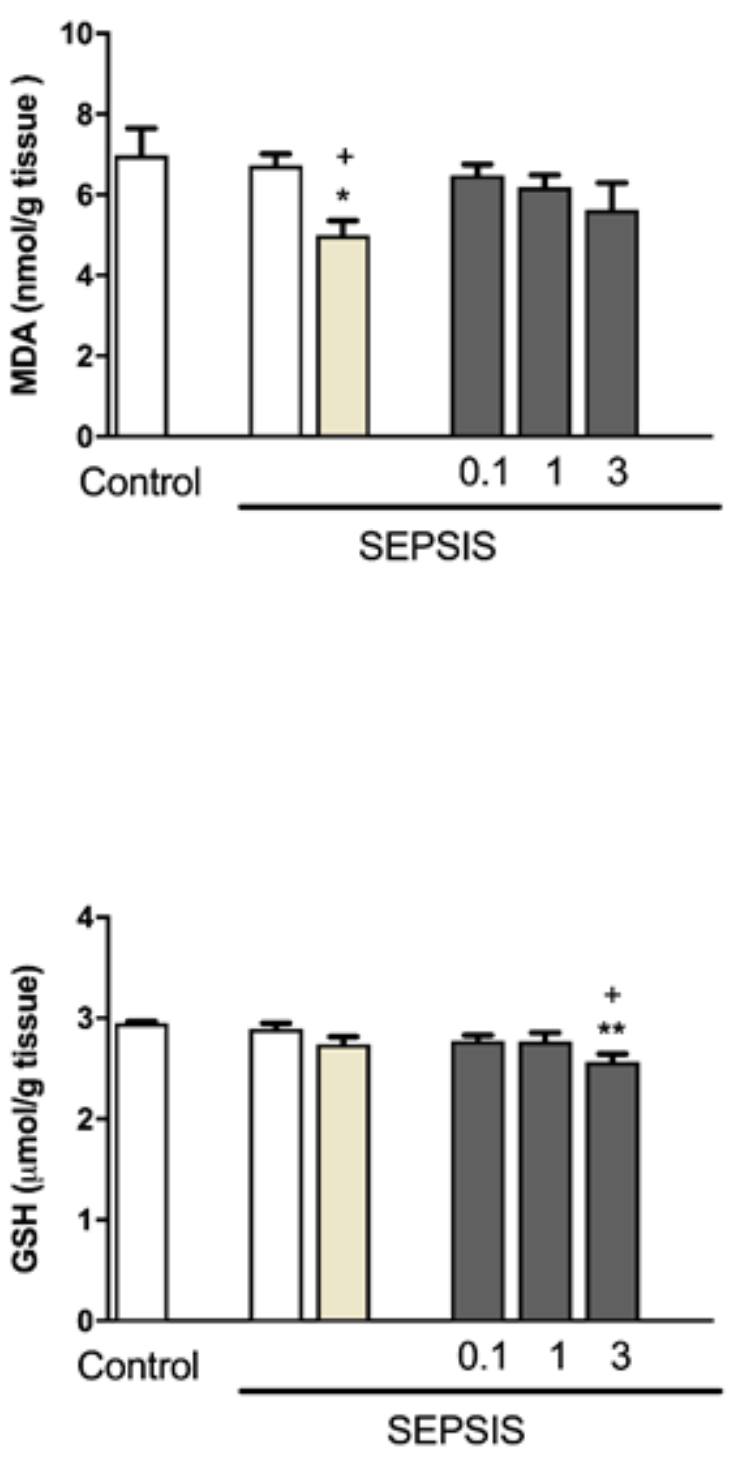

\section{LIVER}
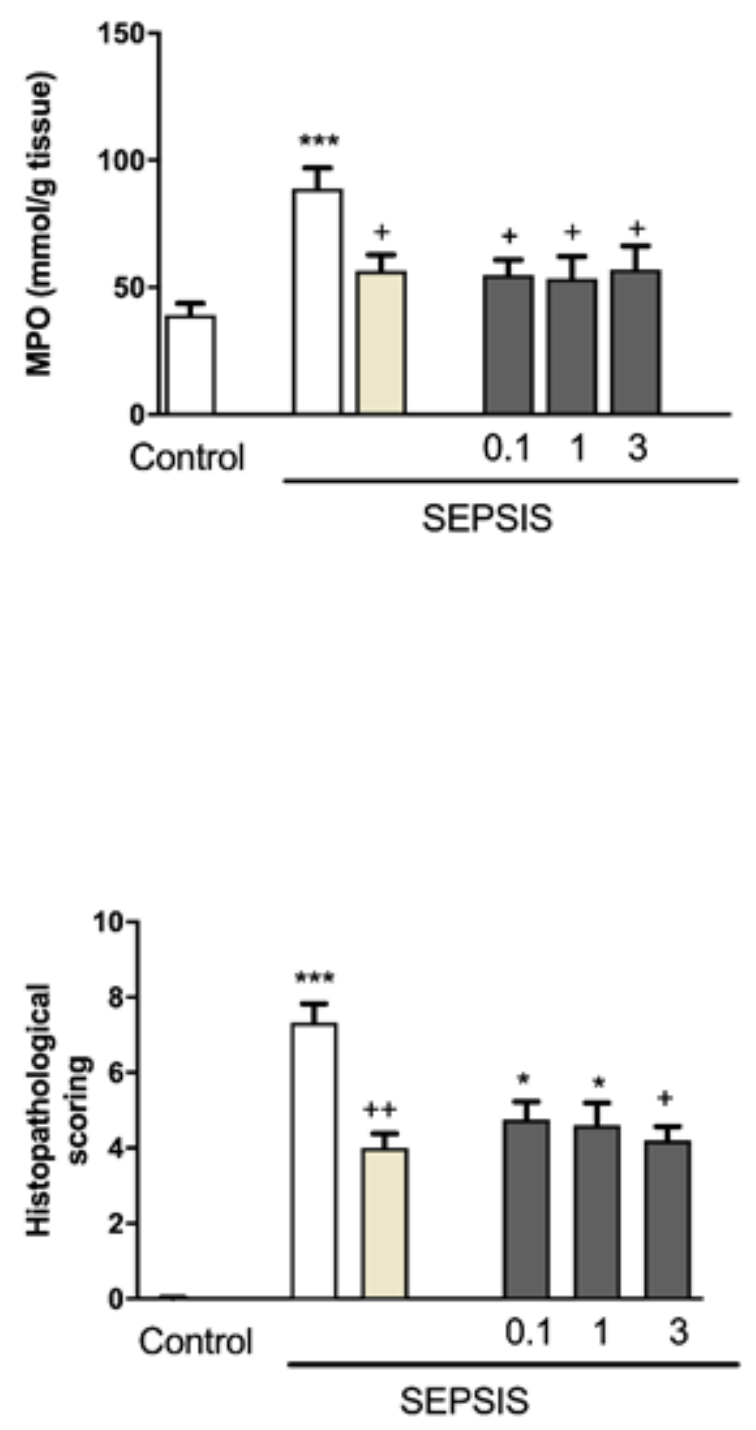

Figure 6

Levels of malondialdehyde (MDA), myeloperoxidase (MPO) activity, glutathione (GSH) and histopathological scores in the liver tissues of control rats and septic rats injected subcutaneously with either saline, etanercept plus antibiotic $(E T+C)$ or neuropeptide W (NPW, $0.1,1$ and $3 \mu \mathrm{g} / \mathrm{kg}$ ) immediately after sepsis induction, and at the 12th and 24th $h .{ }^{*} p<0.05$, ${ }^{* \star} \mathrm{p}<0.001$ compared to control group, $+p<0.05,++p<0.01$, compared to saline-treated sepsis group. 
Saline

$\square$ NPW $(\mu \mathrm{g} / \mathrm{kg})$

$\square \mathrm{ET}+\mathrm{C}$
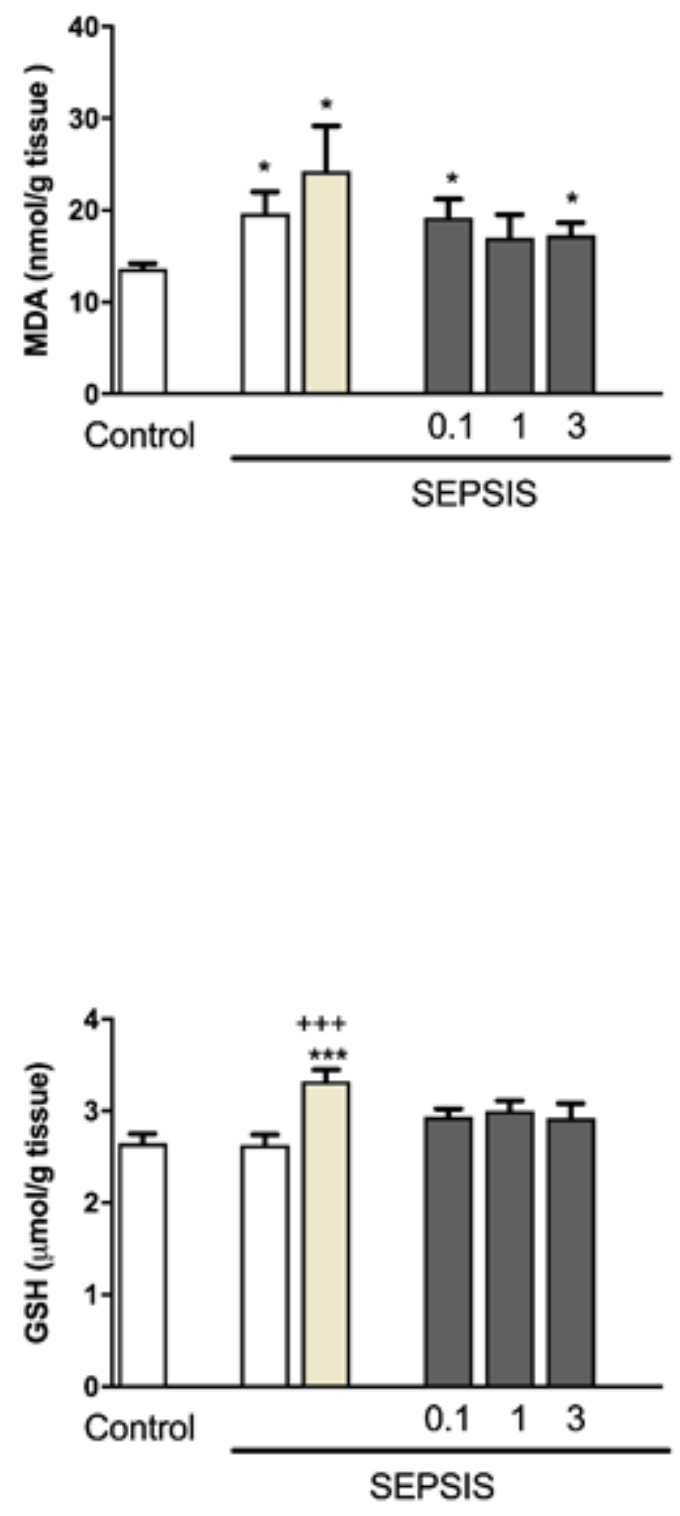

KIDNEY
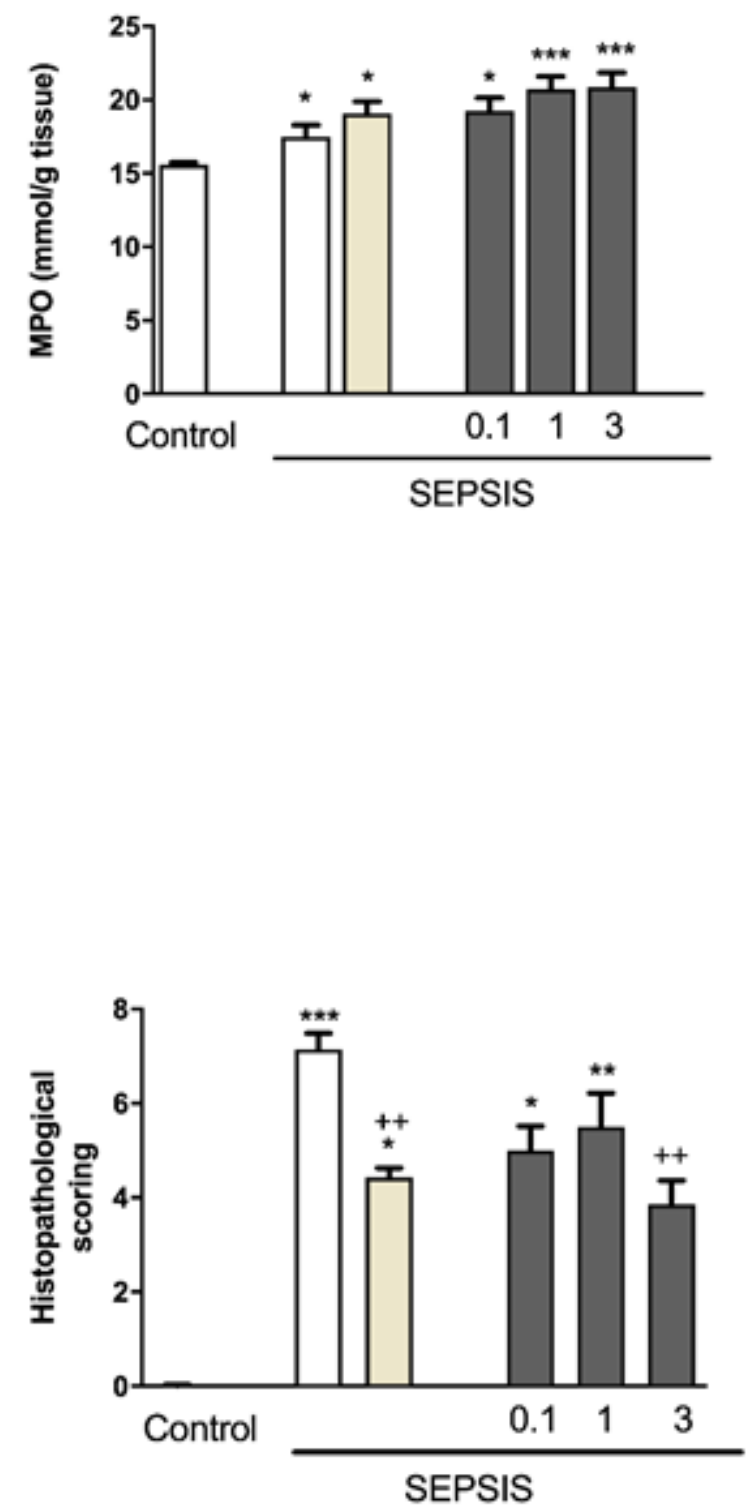

\section{Figure 7}

Levels of malondialdehyde (MDA), myeloperoxidase (MPO) activity, glutathione (GSH) and histopathological scores in the kidney tissues of control rats and septic rats injected subcutaneously with either saline, etanercept plus antibiotic $(E T+C)$ or neuropeptide W (NPW, $0.1,1$ and $3 \mu \mathrm{g} / \mathrm{kg}$ ) immediately after sepsis induction, and at the 12th and 24th $\mathrm{h} .{ }^{*} \mathrm{p}<0.05$, ${ }^{\star \star} \mathrm{p}<0.01,{ }^{\star \star \star} \mathrm{p}<0.001$, compared to control group, $++p<0.01,+++p<0.001$ compared to saline-treated sepsis group. 
BRAIN

Saline

$\square$ NPW $(\mu \mathrm{g} / \mathrm{kg})$

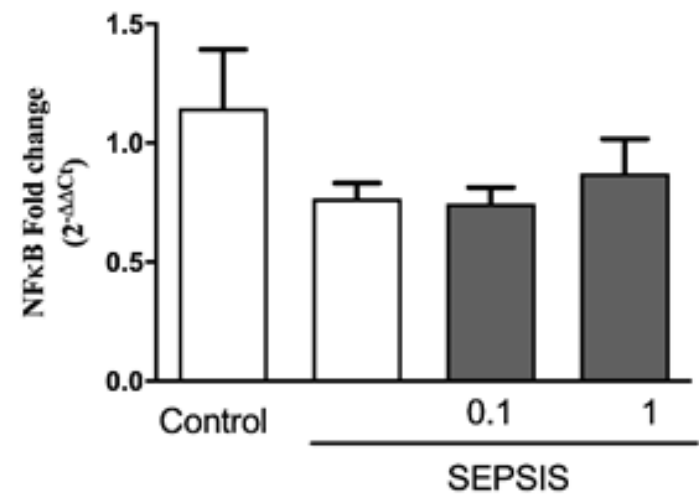

HEART

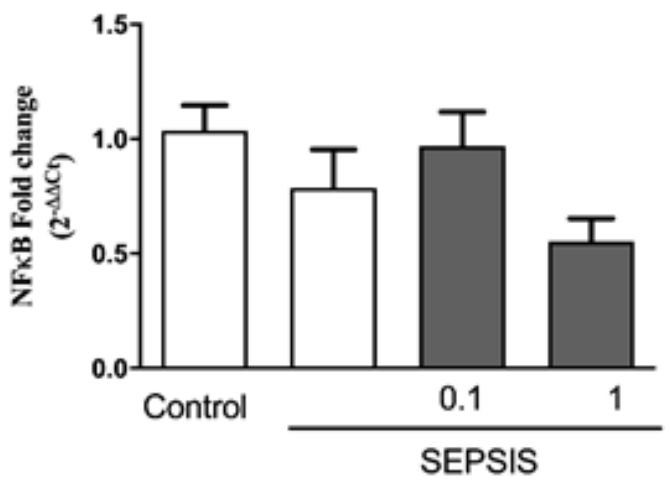

LIVER

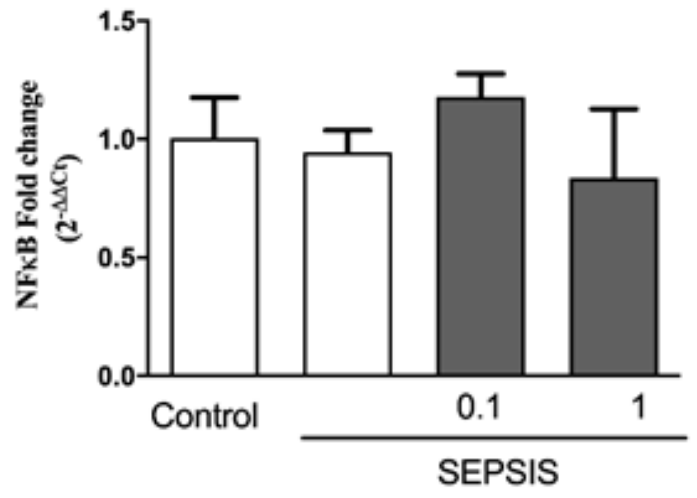

LUNG

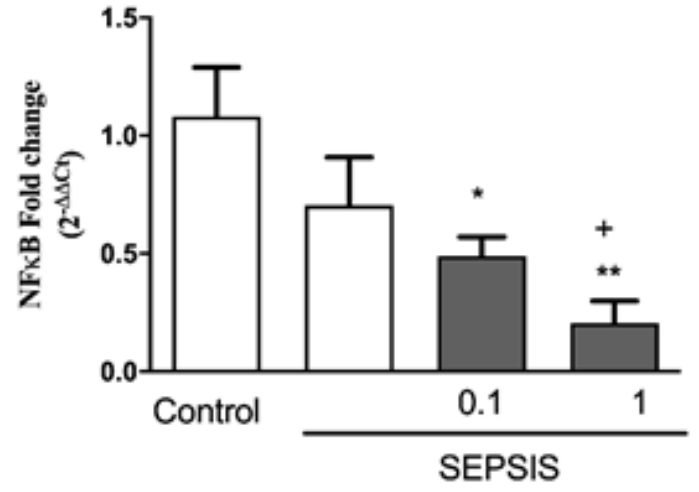

KIDNEY

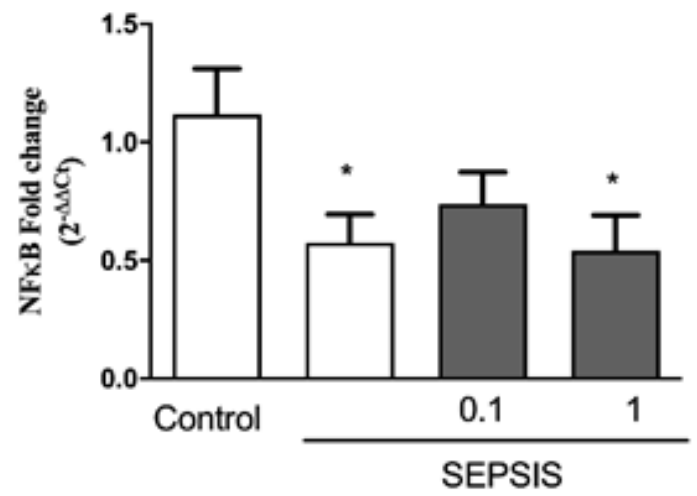

Figure 8

NFkB mRNA expressions in the brain, heart, lung, liver and kidney tissues of control rats and septic rats injected subcutaneously with either saline or neuropeptide W (NPW, 0.1 and $1 \mu \mathrm{g} / \mathrm{kg}$ ) immediately after sepsis induction, and at the 12th and 24th $h$. ${ }^{*} p<0.05,{ }^{*} p<0.01$, compared to control group, $+p<0.05$, compared to saline-treated sepsis group. 